\title{
A longitudinal study of the prevalence and characteristics of breast disorders detected by clinical breast examination during pregnancy and six months postpartum in Ibadan, Southwestern Nigeria
}

\author{
Stella O. Odedina ${ }^{1 *}$ D, IkeOluwapo O. Ajayi ${ }^{1 *}$, Adenike Adeniji-Sofoluwe², Imran O. Morhason-Bello ${ }^{3,4}$,
} Dezheng Huo ${ }^{5}$, Olufunmilayo I. Olopade ${ }^{6}$ and Oladosu A. Ojengbede ${ }^{3,4}$

\begin{abstract}
Background: Breast disorders cause great anxiety for women especially when they occur in pregnancy because breast cancer is the most common cause of cancer related deaths in women. Majority of the disorders are Benign Breast Diseases (BBD) with various degrees of associated breast cancer risks. With increasing breast cancer awareness in Nigeria, we sought to determine the prevalence and characteristics of breast disorders among a cohort of pregnant women.

Methods: A longitudinal study of 1248 pregnant women recruited in their first trimester- till 26 weeks gestational age consecutively from selected antenatal clinics (ANCS), in Ibadan, Southwest Nigeria. A pretested interviewer- administered questionnaire was used to collect information at recruitment. Clinical Breast Examination (CBE) using MammaCare ${ }^{\oplus}$ technique was performed at recruitment and follow up visits at third trimester, six weeks postpartum and six months postpartum. Women with breast disorders were referred for Breast Ultrasound Scan (BUS) and those with Breast Imaging Reporting and Data System (BIRADS) $\geq 4$ had ultrasound guided biopsy. Statistical analysis was performed using Stata version 14.

Results: Mean age of participants was $29.7 \pm 5.2$ years and mean gestational age at recruitment was $20.4 \pm 4.4$ weeks. Seventy-two participants (5.8\%) had a past history of BBD and 345 (27.6\%) were primigravidae. Overall, breast disorder was detected among 223 (17.9\%) participants and 149 (11.9\%) had it detected at baseline. Findings from the CBE showed that 208 (69.6\%) of 299 breast disorders signs found were palpable lumps or thickenings in the breast, 28 (9.4\%) were persistent pain, and 63 (21.1\%) were abscesses, infection and mastitis. Twenty out of 127 (15.7\%) participants who had BUS performed were classified as BIRADS $\geq 3$. Lesions found by BUS were reactive lymph nodes (42.5\%), prominent ducts (27.1\%), fibroadenoma (9.6\%), breast cysts (3.8\%) and fibrocystic changes (2.5\%). No malignant pathology was found on ultrasound guided biopsy.

Conclusions: Breast lump is a major breast disorder among pregnant women attending antenatal clinics in lbadan. Routine clinical breast examination and follow up of pregnant women found with breast disorders could facilitate early detection of pregnancy associated breast cancer in low resource settings.
\end{abstract}

Keywords: Benign breast diseases, Pregnant women, Antenatal clinics, Longitudinal, Clinical breast examination, Post-partum

\footnotetext{
* Correspondence: stellakinleye@yahoo.com; ikeajayi2003@yahoo.com

${ }^{1}$ Department of Epidemiology and Medical Statistics, Faculty of Public Health,

University of Ibadan, Ibadan, Nigeria

Full list of author information is available at the end of the article
}

(c) The Author(s). 2018 Open Access This article is distributed under the terms of the Creative Commons Attribution 4.0 International License (http://creativecommons.org/licenses/by/4.0/), which permits unrestricted use, distribution, and reproduction in any medium, provided you give appropriate credit to the original author(s) and the source, provide a link to the Creative Commons license, and indicate if changes were made. The Creative Commons Public Domain Dedication waiver (http://creativecommons.org/publicdomain/zero/1.0/) applies to the data made available in this article, unless otherwise stated. 


\section{Background}

Breast disorders are very common among women [1-3] and some are known to be associated with increased risk for breast cancer [4-6]. Few studies have looked into benign breast diseases in sub-Saharan Africa [4]. In Nigeria, most studies have focused on histopathology characteristics of benign breast disease [7, 8]. Few studies have explored the clinical diagnosis of breast disorders $[3,9]$.

During pregnancy, many women suffer from different types of breast problems including fibroadenoma, mastitis, breast abscess, galactocoele and pregnancy associated breast cancer (PABC) which is very common because of the relative young age at breast cancer diagnosis in the population [9-13]. Pregnant women with breast problems should be investigated thoroughly and this should be done at regular intervals $[10,12,14]$. Pregnancy associated breast cancer even though rare is known to be very aggressive with poor outcomes attributed to diagnostic delays $[12,15,16]$.

Breast cancer screening is a viable option for early detection of breast cancer [3]. In sub-Saharan Africa, screening programmes are non-organized and implementation of such programmes has been very challenging $[9,17,18]$. Breast screening approach requires triple assessment before excluding breast cancer, and this is also applicable in pregnancy. Clinical breast examination (CBE) should not be done alone, further investigations such as Breast Ultrasound Scan and ultrasound guided biopsy are required and are safe for pregnant and lactating women $[9,14,19,20]$.

Our study is the first to examine women for breast disorders at intervals in pregnancy and postpartum using CBE, BUS and ultrasound guided biopsy when necessary and it determined the prevalence and characteristics of breast disorders in pregnancy and 6 months postpartum A similar study was conducted previously in the eastern part of Nigeria and its objective was to compare the detection rate of CBE with BUS among pregnant women [9]. Due to the link or relation between benign breast diseases and breast cancer risk, understanding the pattern of breast disease is an important step towards formulation of policies for breast screening and planning in Nigeria.

The study aimed to determine the prevalence and characteristic of breast disorders as detected by CBE and classified by ultrasonography and ultrasound guided biopsy in pregnancy and six months postpartum. The secondary aim of the study was to identify differences in the characteristics of women with breast disorders and women without breast disorders. The hypothesis was that breast disorders detection in pregnancy or during postpartum can aid early diagnosis of pregnancy-associated breast cancer.

\section{Methods}

Study setting

Study centers and settings include the antenatal and postnatal clinics of the University College Hospital (UCH), Adeoyo Maternity Hospital (AMH) and Primary Health Centre (PHC) Agbongbon in Ibadan representing tertiary, secondary and primary public health facilities based on three level of care in Ibadan, Southwestern Nigeria. Ibadan is the capital and a city in Oyo State, Nigeria. Oyo state has a population of 5,580,894 according to 2006 census and 1,633,333 are reproductive age women (15-49 years) [21]. Therefore, Ibadan metropolis with a population of $1,343,147$ has an estimate of 392,733 reproductive age women. Majority of the people in Ibadan are of Yoruba ethnicity. Both UCH and AMTH are main public health care facilities rendering maternal care services to majority of women in the city.

\section{Study design and study population}

This is a longitudinal study of pregnant women attending antenatal clinics (ANCs) in Ibadan, Nigeria. All pregnant women within first trimester till- 26 weeks gestational age were eligible. Pregnant women with previous breast cancer history were excluded.

\section{Sample size and sampling}

The study sample size of 970 was calculated using the sample size formula for estimating relative risk [22]. Several proportions of relative risk factors for breast diseases were calculated and the highest sample size using age at menarche with a relative risk of 0.80 as estimate was picked [23]. The sample size was calculated assuming a type 1 error of $5 \%$ and accounting for a non-response rate of $20 \%$.

After obtaining informed consent, participants were consecutively recruited during their $\leq 26$ weeks gestational age. They were followed up in their third trimester, six weeks postpartum and six months postpartum considering variations in hormones and the difficulty in detecting lumps in pregnancy and during lactation.

\section{Data collection methods}

A pretested and face validated questionnaire was used to collect information on socio-demographic characteristics, medical history, lifestyle and reproductive variables. Test-retest method was used to ascertain the reliability of the questionnaire. The questionnaire was administered to ten pregnant women twice with two-week interval at a different health centre (PHC Bashorun) from the study centre. Variables from the questionnaires were computed. Total composite scores for pre-test and post-test were then compared. A correlation value of 0.9 was achieved.

Research nurses and research assistants were trained prior to the commencement of the study. Research Nurses were introduced to the study and instructed on 
breast health and MammaCare ${ }^{\bullet}$ method of Breast Self Examination (BSE) and CBE. MammaCare method is validated and recommended for effective CBE and BSE [24]. It involves the use of tactile senses and it follows $5 \mathrm{P}$ rule for complete breast examination. The 5Ps are palpation, pressure, pattern, perimeter and position. The pads of three middle fingers are used for palpation, three levels of pressure are applied at a spot (light, middle, and deep), breasts are examined using a vertical strip pattern movement, perimeter of the breast, extending to the axilla is outlined and examined, and finally, both breasts should be examined in the cahan and supine positions.

Trained Research nurses practiced on breast models and examined human volunteers attending ANC at the University College Hospital, Ibadan. During the training, the Clinical Breast Examination tool, which included a checklist, was developed and reviewed to ensure consistency and reduce selection bias while defining breast disorders. In addition, inter rater reliability analysis was performed by rating each nurse performance and agreement on detecting lumps on a breast model. The inter-rater reliability for the raters kappa coefficient was $0.55(p<0.001)$, which represents a moderate agreement among the Nurses.

The study spans from June 2015 to September 2017. All study participants were taught how to examine their breasts. Clinical breast exam using MammaCare ${ }^{\circ}$ technique was performed by trained nurses at recruitment and at follow up visits in all centers. Research assistants administered the questionnaire after obtaining informed consent at recruitment. Participants were considered to have breast disorders if breast changes such as palpable lumps, inflammation, persistent pain and/or abnormal nipple discharge were found using the checklist. Those with breast disorders were referred for BUS and ultrasound guided biopsy as necessary. All study participants were taught how to examine their breast at recruitment.

Breast ultrasound scan was performed by a consultant radiologist at the Radiology Department of $\mathrm{UCH}$, and a private facility located in Ibadan. The BUS assessment was made using Breast Imaging Reporting and Data System (BIRADS). Ultrasound guided biopsy was performed for those with BIRADS 4 lesion by a Consultant Radiologist and biopsy read at the Pathology Department of UCH.

\section{Statistical analysis}

Descriptive statistics was used for calculating the percentages. Generalized Linear Marginal Model (GLMM) with Generalized Estimating Equation (GEE) was used to determine the trend of breast disorders in pregnancy and in lactation and it was also used to determine association between selected patients characteristics with breast disorder status. The GLMM assumed an exchangeable variance covariance structure. Variables whose $p$-value was $<0.05$ from bivariate analysis were selected into the final GLMM.
All statistical analyses were done using Stata version 14. (Texas, USA).

Ethical approval was gotten from the University of Ibadan/University College Hospital (UI/UCH) Ethics Committee and the Oyo State Ministry of Health Ethics Committee, Ibadan, Nigeria and all participating women gave their written informed consent.

\section{Results}

\section{Characteristics of study participants}

A total of 1248 pregnant women within ages 16-46 were recruited. The mean \pm SD age was $29.7 \pm 5.2$ years and mean \pm SD gestational age at recruitment was $20.4 \pm$ 4.4 weeks. Seven hundred and eight (56.6\%) women had above secondary level education. All study participants were of African heritage with majority (92.5\%) from Yoruba ethnic group, $72(5.8 \%)$ had a history of breast disease, $345(27.6 \%)$ were primigravidae and 58 (4.7\%) had family history of cancer (Table 1 ).

One hundred and eighty three $(14.7 \%)$ of study participants had ever done CBE prior to the study, but only 50 (27.3\%) from these women had it done during ANC booking or registration. Other places mentioned were: whenever they noticed any breast change and they made breast complaint to health practitioners 55 (30.1\%), during normal routine check up 20 (10.9\%), and during breast health sensitization or seminar programmes in their community, place of worship or place of work 8 (4.4\%).

\section{Prevalence and pattern of breast disorders CBE findings}

All the pregnant women had CBE done during their clinic visit at recruitment and 701 (56.2\%) had CBE done in their third trimester. At postpartum, 922 (73.9\%) were seen at their various postnatal clinics and those who could not make their clinic visit were called at 6 weeks postpartum also, $728(58.3 \%)$ were seen or called at 6 months postpartum (Fig. 1). Figure 2 shows the frequencies of CBE experienced by study participants, 606 (48.6\%) had three $\mathrm{CBE}$ and 354 (28.4\%) had four CBE. A total of 223 (17.9\%) women had breast disorders detected throughout the length of the entire study. At baseline, 149 (11.9\%) had breast disorder detected while 74 (6.7\%) of those without breast disorders had it detected at follow up. An incidence rate of 9.2 per 100 person years was found. Women found with breast disorders at baseline had a mean age of $28.2 \pm$ 5.4 years. For all women with breast disorders at baseline and follow up, the mean age was $28.5 \pm 5.3$ years. Palpable masses comprises 208 (69.6\%) of all breast disorders detected and $63(21.1 \%)$ were abscesses, infection and mastitis. Table 2 shows the proportion of different breast disorders found at recruitment and at follow up. One hundred and fifty seven (70.4\%) women of those found with breast disorders overall in the study had only a form of breast disorders while 66 (29.6\%) had two or more forms 
Table 1 Characteristics of study participants

\begin{tabular}{|c|c|c|c|}
\hline & Breast Disorders & Breast Disorders & Total \\
\hline & (yes) $N=223$ & (no) $N=1025$ & $N=1248$ \\
\hline & $n(\%)$ & $n(\%)$ & \\
\hline \multicolumn{4}{|l|}{ Age group (years) } \\
\hline$<25$ & $55(24.7)$ & $149(14.5)$ & $204(16.4)$ \\
\hline $25-29$ & 75 (33.6) & 337 (32.9) & $412(33.0)$ \\
\hline $30-34$ & $58(26.0)$ & $325(31.7)$ & $383(30.7)$ \\
\hline$>34$ & $35(15.7)$ & $214(20.9)$ & $249(19.9)$ \\
\hline \multicolumn{4}{|l|}{ Health Facility } \\
\hline PHC & $25(11.2)$ & $77(7.5)$ & $102(8.2)$ \\
\hline $\mathrm{AMH}$ & $160(71.8)$ & $625(60.9)$ & 785 (62.9) \\
\hline $\mathrm{UCH}$ & $38(17.0)$ & $323(31.5)$ & 361 (28.9) \\
\hline \multicolumn{4}{|l|}{ Education } \\
\hline None/Primary & $22(9.9)$ & $62(6.1)$ & $84(6.7)$ \\
\hline Secondary & $105(47.1)$ & $351(34.2)$ & $456(36.5)$ \\
\hline Polytechnic & $47(21.1)$ & $215(20.9)$ & $262(20.9)$ \\
\hline B. Sc./HND & $42(18.8)$ & $303(29.7)$ & $345(27.6)$ \\
\hline Postgraduate & $7(3.1)$ & $94(9.2)$ & $101(8.1)$ \\
\hline \multicolumn{4}{|l|}{ Ethnicity } \\
\hline Yoruba & $206(92.4)$ & $948(92.5)$ & 1154 (92.5) \\
\hline Ibo & $9(4.0)$ & $39(3.8)$ & $48(3.9)$ \\
\hline Hausa & $3(1.4)$ & $9(0.9)$ & $12(0.9)$ \\
\hline Others & $5(2.2)$ & $29(2.8)$ & $34(2.7)$ \\
\hline \multicolumn{4}{|l|}{ Occupation $^{*} N=1247$} \\
\hline Professionals & $8(3.6)$ & $88(8.6)$ & $96(7.7)$ \\
\hline Civil servants & $47(21.1)$ & $342(33.4)$ & 389 (31.2) \\
\hline Full time housewife, unemployed & $26(11.7)$ & $99(9.7)$ & $125(10.0)$ \\
\hline \multicolumn{4}{|l|}{ Artisan, small scale entrepreneur, } \\
\hline labourers & $142(63.7)$ & $495(48.3)$ & $637(51.1)$ \\
\hline \multicolumn{4}{|l|}{ Family history of any cancer type } \\
\hline Yes & $11(4.9)$ & $47(4.6)$ & $58(4.6)$ \\
\hline No & $212(95.1)$ & $978(95.4)$ & $1190(95.4)$ \\
\hline \multicolumn{4}{|l|}{ Ever had benign breast disease } \\
\hline Yes & $19(5.2)$ & $53(5.2)$ & $72(5.8)$ \\
\hline No & $204(91.5)$ & $972(94.8)$ & $1176(94.2)$ \\
\hline \multicolumn{4}{|l|}{ No of pregnancies } \\
\hline 1 & $72(32.3)$ & $273(26.6)$ & $345(27.6)$ \\
\hline 2 & $59(26.5)$ & $249(24.3)$ & $308(24.7)$ \\
\hline$>2$ & $92(41.3)$ & $503(49.1)$ & $595(47.7)$ \\
\hline Age at menarche (years) ${ }^{*} N=1239$ & $15.3 \pm 2.0$ & $15.1 \pm 2.3$ & $15.1 \pm 2.2$ \\
\hline Height $^{*} N=1211$ & $158.5 \pm 6.7$ & $159.4 \pm 6.6$ & $159.3 \pm 6.6$ \\
\hline Weight $(\mathrm{kg})^{*} N=1209$ & $63.9 \pm 12.2$ & $67.5 \pm 13.0$ & $66.8 \pm 12.9$ \\
\hline
\end{tabular}


Table 1 Characteristics of study participants (Continued)

\begin{tabular}{llll}
\hline & $\begin{array}{l}\text { Breast Disorders } \\
\text { (yes) } N=223 \\
n(\%)\end{array}$ & $\begin{array}{l}\text { Breast Disorders } \\
(\text { no) } N=1025 \\
n(\%)\end{array}$ \\
\hline $\begin{array}{l}\text { BMl kg/m=1248 } \\
<18\end{array}$ & $6(2.8)$ & $12(1.2)$ & $18(1.5)$ \\
$18-24.9$ & $109(50.7)$ & $423(42.9)$ & $532(44.3)$ \\
$25-29.9$ & $60(27.9)$ & $318(32.2)$ & $378(31.5)$ \\
$30-34.9$ & $32(14.9)$ & $176(17.8)$ & $208(17.3)$ \\
$>34.9$ & $8(3.7)$ & $58(5.9)$ & $66(5.5)$ \\
\hline
\end{tabular}

PHC Primary Health Centre Agbongbon, AMTH Adeoyo Maternity Teaching Hospital, UCH University College Hospital, ${ }^{*}$ missing $N \neq 1248$

(Fig. 3). Breast disorders were identified on the left breast 87 (39.0\%), on the right breast $83(37.0 \%)$, and in both breasts 54 (24.0\%).

\section{Breast ultrasound scan findings}

One hundred and twenty seven (61.7\%) women referred did BUS. Eighteen (14.2\%) had BIRADS 3 and 98 (77.2\%) had BIRADS 2 (Table 3).

Three women whose BUS reports were suspicious of malignancy did ultrasound-guided biopsy. Impressions from ultrasound findings showed that most had reactive lymph nodes (42.5\%) and prominent ducts (27.1\%). Other findings were fibroadenoma (9.6\%), fibrocystic changes $(2.5 \%)$ and breast cysts $(3.8 \%)$. Figure 4 shows a BUS image of a woman diagnosed with fibroadenoma and breast cyst. Forty four (34.6\%) masses or structures were found by the scan from the 127 that had BUS done, of which $14(31.8 \%)$ were found to be on the left breast, $13(29.5 \%)$ on the right breast and $17(38.6 \%)$ in both breasts. Table 4 shows in detail, impressions from the BUS based on time detected in pregnancy or lactation by $\mathrm{CBE}$. The median time from $\mathrm{CBE}$ at recruitment to

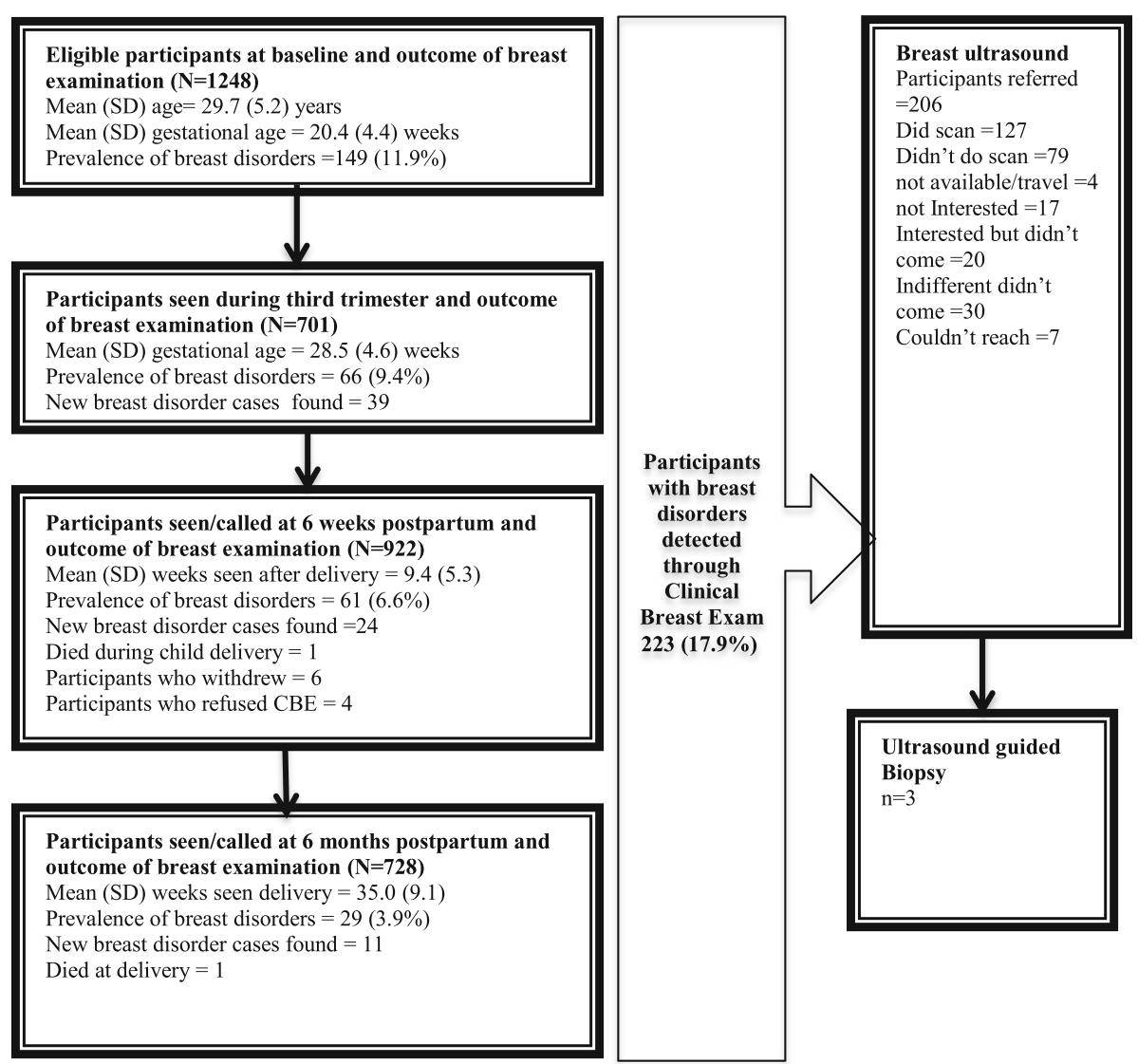

Fig. 1 Participants flow chart with proportion seen at various visits 


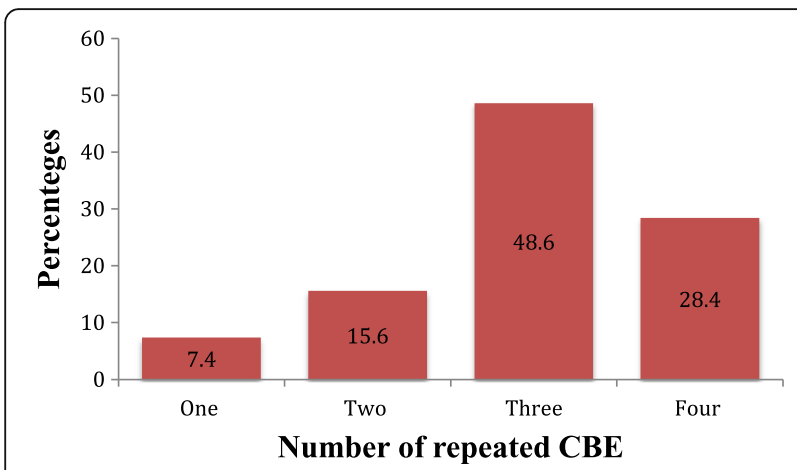

Fig. 2 Repeated CBE as experienced by study participants $N=1248$

BUS was $191 \pm 141$ days. The period between breast disorder detection by CBE and having BUS done was long as depicted by the median time above. This must have accounted for a lesser proportion of masses found by BUS compared to CBE.

\section{Ultrasound guided biopsy}

No malignant pathologies were found in the biopsy specimen of the three women referred for breast ultrasound guided biopsy. Diagnoses made were florid adenosis, lactational adenoma and fibroadenoma/pregnancy associated changes with infection.

\section{Changes in the breast with time and associated patients characteristics}

The prevalence of breast disorders detected by CBE reduces with time on the generalized linear model with GEE $(p<0.001)$. Compared to the risk of detecting breast disorders by $\mathrm{CBE}$ at recruitment, the odds ratio for breast disorders was 0.80 (95\% CI: $0.62-1.03)$ at third trimester, 0.54 (95\% CI: $0.41-0.69)$ at 6 weeks postpartum and 0.35 (95\% CI:0.25-0.49) at 6 months postpartum.

Table 5 shows the association between selected patients characteristic and breast disorders in pregnancy and six months postpartum adjusting for variables significant at 5\% $(p=0.05)$ from bivariate analysis and some important variables. Variables included in the final GLM model were time, age group, number of pregnancies, study centre,

Table 2 Findings from Clinical Breast Examination (CBE) of participants

\begin{tabular}{lll}
\hline & $\begin{array}{l}\text { Overall } N=299 \\
n(\%)\end{array}$ & $\begin{array}{l}\text { Baseline only } N=195 \\
n(\%)\end{array}$ \\
\hline Palpable masses & $208(69.6)$ & $141(72.3)$ \\
Abscesses, Infection, Mastitis & $63(21.1)$ & $38(19.5)$ \\
Persistent pain & $28(9.4)$ & $16(8.2)$ \\
Palpable masses with pain $^{\text {a }}$ & $15(5.0)$ & $6(3.1)$ \\
Infection with pain $^{\text {a }}$ & $4(1.3)$ & $2(1.0)$ \\
\hline
\end{tabular}

${ }^{a}$ Overlapping signs and symptoms

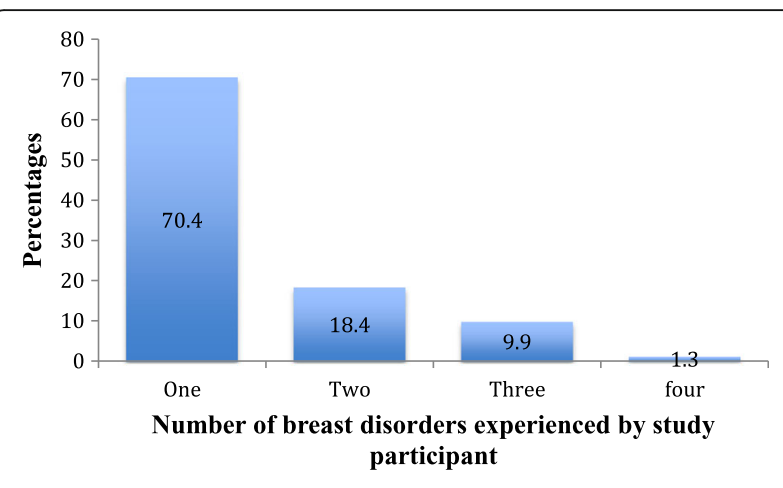

Fig. 3 Breast disorders as experienced by study participants $N=223$

weight, education, occupation, ever had history of benign breast diseases, BMI (group) and relative history of any cancer type. Women who had B.Sc. equivalent level of education had lower odds of breast disorders compared to those with none or primary level of education $(\mathrm{aOR}=0.47$, $95 \% \mathrm{CI}=0.24-0.89$ ), women with a history of benign breast diseases had higher odds of breast disorders compared to those without the history ( $\mathrm{aOR}=2.13,95 \% \mathrm{CI}=1.25-3.64)$, and women with three or more pregnancies had higher odds of breast disorders compared to those with one. $(\mathrm{aOR}=0.65,95 \% \mathrm{CI}=0.43-0.97)$.

\section{Discussion}

Benign breast diseases are very common among young women in their reproductive ages, irrespective of whether pregnant, lactating or not $[1,2]$. The mean age of women with breast disorders in this study was 28.5 years. This falls within the age range of women with benign breast diseases in other studies conducted respectively in Warri, Benin, Lagos and Ile-Ife, Nigeria [8, 25-27].

At baseline, the prevalence of breast disorders in pregnancy detected by $\mathrm{CBE}$ was $11.9 \%$. Throughout pregnancy and 6 months postpartum, the total prevalence of breast disorder was 17.9\%. Findings from some

Table 3 Ultrasound Breast Imaging Reporting and Data System (BIRADS) classification of breast disorders $(N=127)$

\begin{tabular}{lll}
\hline $\begin{array}{l}\text { BIRADS } \\
\text { Categories }\end{array}$ & Descriptors & $n(\%)$ \\
\hline BIRADS 0 & Needs additional imaging evaluation & $0(0.0)$ \\
BIRADS 1 & Negative & $9(7.1)$ \\
BIRADS 2 & Benign findings & $98(77.2)$ \\
BIRADS 3 & $\begin{array}{l}\text { Probably benign findings; short interval } \\
\text { follow up suggested }\end{array}$ & $18(14.2)$ \\
BIRADS 4 & $\begin{array}{l}\text { Suspicious abnormality; biopsy should } \\
\text { be considered }\end{array}$ & $2(1.6)$ \\
BIRADS 5 & $\begin{array}{l}\text { Highly suggestive of malignancy; appropriate } \\
\text { BIRADS 6 }\end{array}$ & $0(0.0)$ \\
& Known biopsy-proven malignancy; appropriate & $0(0.0)$ \\
\hline
\end{tabular}




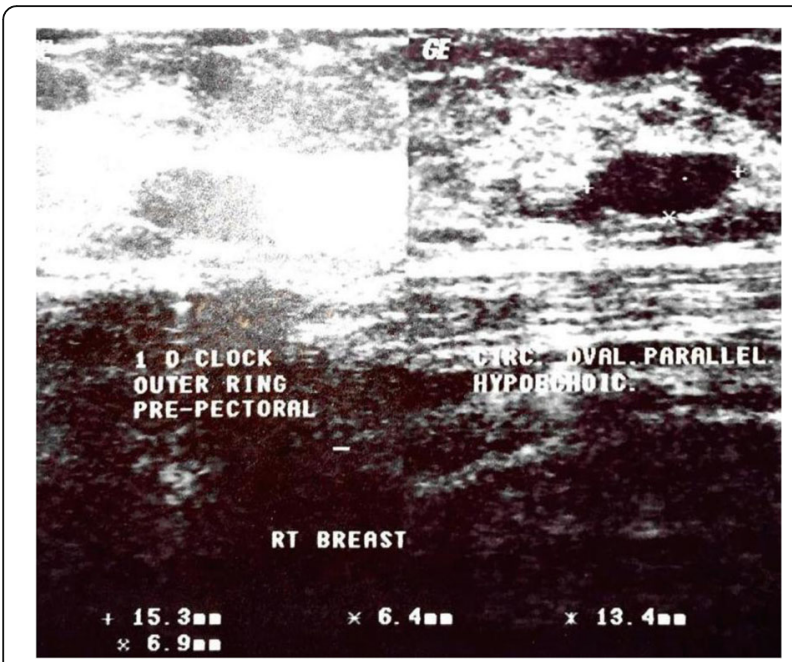

Fig. 4 Circumscribed oval hypoechoic masses in parallel orientation in the right breast seen at $1 \mathrm{O}^{\prime}$ clock position in the middle-outer ring and pre-pectoral region and at $12 \mathrm{O}^{\prime}$ clock position in the inner ring with posterior enhancement- fibroadenoma and breast cysts

community surveys in Africa, whereby breast screening was carried out among women in general reported lesser proportions. For example, a study conducted in Ghana found $4.8 \%$ of 1419 premenopausal women had clinically palpable breast lumps of which screening was conducted by mammocare ${ }^{\curvearrowleft}$ experts [28]. Abuidris, et al. [17] in a house to house breast screening pilot survey in Sudan reported $1.3 \%$ of their participants to have breast abnormalities detected by trained local volunteers. However, a prevalence of $5.3 \%$ of breast lesions detected by repeat $\mathrm{CBE}$ in pregnancy and postpartum was reported by an analytical cross-sectional study conducted among pregnant women during antenatal clinic in Abakaliki teaching hospital, Ebonyi, Nigeria [9], a higher proportion of women with breast disorders detected through CBE was found in this study.
A higher prevalence of breast disorders in pregnancy than non-pregnant state is not unusual because of the influence of female's hormones and growth factors causing several physiological changes during pregnancy and lactation [12, 29, 30]. Reasons for a higher prevalence in our study could be due to longitudinal design that gave more time for more breast disorders to be detected. Another plausible reason is the inter-observer variation by nurses on use of MammaCare ${ }^{\circledast}$ for $\mathrm{CBE}$ at the 3 study centers. Despite these possibilities, Mammacare ${ }^{\oplus}$ techniques used has been scientifically validated for $\mathrm{CBE}$ and it has been proven to detect lumps as small as $0.3 \mathrm{~cm}$ [24].

In Nigeria, majority of breast cancer cases are known to occur among women in their reproductive ages and the cancer types associated has been proven to be very aggressive [1, 2, 31]. A rise in the incidence of breast disease in Nigeria has also been reported [25] and the incidence is likely to increase due to the increase in breast cancer awareness. About $20 \%$ of pre-menopausal breast cancer cases occurred during pregnancy and within 5 years postpartum in a Nigerian study [32]. An incidence rate of 9.2 per 100 person years for breast disorders was noted in our study. Therefore, close attention and monitoring of pregnant and lactating women with breast problems is necessary.

Although the prevalence of women with breast disorders was high, interestingly, the risk of having breast disorders detected by CBE in pregnancy for an individual reduces with time over the period of follow up (third trimester, six weeks postpartum, six months postpartum). Some benign breast diseases may have been masked by the increase in breast density or they underwent secretory, cystic and necrotic changes or they simply regress spontaneously after childbirth. Examples of BBD known for these attributes are fibroadenoma and fibrocystic changes found in some non African studies [12, 33, 34].

A palpable mass is the most common sign of breast disease detected by $\mathrm{CBE}$ as reported by studies conducted in

Table 4 Findings from Breast ultrasound scan reports showing proportion of breast disorders detected by CBE at recruitment and follow up

\begin{tabular}{lllll}
\hline BUS Impressions & $\begin{array}{l}\text { Recruitment } \\
n(\%)\end{array}$ & $\begin{array}{l}\text { Third trimester } \\
n(\%)\end{array}$ & $\begin{array}{l}\text { Six weeks postpartum } \\
n(\%)\end{array}$ & $\begin{array}{l}\text { Six months postpartum } \\
n(\%)\end{array}$ \\
\hline Reactive lymph nodes & $70(44.0)$ & $10(50.0)$ & $10(47.6)$ & $2(22.2)$ \\
Prominent ducts & $39(24.5)$ & $7(35.0)$ & $6(28.6)$ & $4(44.4)$ \\
Fibro adenoma & $19(11.9)$ & $2(10.0)$ & $1(4.8)$ & $0(0.0)$ \\
Fibrocystic changes & $4(2.5)$ & $1(5.0)$ & $0(0.0)$ & $0(0.0)$ \\
Breast cyst/complex cyst & $5(3.1)$ & $0(0.0)$ & $2(9.5)$ & $0(0.0)$ \\
Infected dermal inclusion cyst/ sebaceous cyst & $4(2.5)$ & $0(0.0)$ & $1(4.8)$ & $1(11.1)$ \\
Duct ectasia & $0(0.0)$ & $0(0.0)$ & $0(0.0)$ & $1(11.1)$ \\
Galactocoele & $3(1.9)$ & $0(0.0)$ & $0(0.0)$ & $0(0.0)$ \\
Mastitis & $1(0.6)$ & $0(0.0)$ & & $11.1)$ \\
\hline
\end{tabular}


Table 5 Association of selected patients characteristic with breast disorders in pregnancy and six months postpartum

\begin{tabular}{|c|c|c|c|}
\hline & $\begin{array}{l}\text { Adjusted } \\
\text { Odds ratio }\end{array}$ & $\begin{array}{l}95 \% \text { Confidence } \\
\text { Interval }\end{array}$ & $p$-Values \\
\hline \multicolumn{4}{|l|}{ Age group (years) } \\
\hline$<25$ & 1 (ref) & & \\
\hline $25-29$ & 1.07 & $0.71-1.63$ & 0.737 \\
\hline $30-34$ & 0.98 & $0.60-1.59$ & 0.941 \\
\hline$>34$ & 0.89 & $0.52-1.54$ & 0.682 \\
\hline \multicolumn{4}{|l|}{ Health Facility } \\
\hline $\mathrm{UCH}$ & 1 (ref) & & \\
\hline $\mathrm{AMH}$ & 1.03 & $0.63-1.67$ & 0.918 \\
\hline $\mathrm{PHC}$ & 0.79 & $0.38-1.65$ & 0.535 \\
\hline \multicolumn{4}{|l|}{ Education } \\
\hline None/Primary & 1 (ref) & & \\
\hline Secondary & 0.75 & $0.45-1.26$ & 0.281 \\
\hline Polytechnic & 0.63 & $0.35-1.13$ & 0.120 \\
\hline B. Sc./HND & 0.47 & $0.24-0.89$ & $0.022^{* *}$ \\
\hline Postgraduate & 0.41 & $0.14-1.18$ & 0.100 \\
\hline \multicolumn{4}{|l|}{ Occupation } \\
\hline Professionals & 1 (ref) & & \\
\hline Civil servants & 1.69 & $0.67-3.77$ & 0.252 \\
\hline $\begin{array}{l}\text { Full time housewife, } \\
\text { unemployed }\end{array}$ & 2.70 & $1.05-6.95$ & $0.039^{* *}$ \\
\hline \multicolumn{4}{|c|}{ Artisan, small scale entrepreneur, } \\
\hline labourers & 2.00 & $0.79-5.08$ & 0.143 \\
\hline \multicolumn{4}{|l|}{ Family history of cancer } \\
\hline No & 1 (ref) & & \\
\hline Yes & 1.53 & $0.76-3.06$ & 0.230 \\
\hline \multicolumn{4}{|c|}{ Ever had benign breast disease } \\
\hline No & 1 (ref) & & \\
\hline Yes & 2.13 & $1.25-3.64$ & $0.006^{* *}$ \\
\hline \multicolumn{4}{|l|}{ No of pregnancies } \\
\hline 1 & 1 (ref) & & \\
\hline 2 & 0.91 & $0.61-1.37$ & 0.665 \\
\hline$>2$ & 0.64 & $0.43-0.97$ & $0.036^{* *}$ \\
\hline Weight (kg) & 0.99 & $0.96-0.99$ & 0.085 \\
\hline \multicolumn{4}{|l|}{ BMl kg/m² } \\
\hline $18-24.9$ & 1 (ref) & & \\
\hline$<18$ & 1.56 & $0.49-4.95$ & 0.451 \\
\hline $25-29.9$ & 0.93 & $0.59-1.47$ & 0.766 \\
\hline $30-34.9$ & 1.30 & $0.66-2.58$ & 0.448 \\
\hline$>34.9$ & 1.28 & $0.37-4.46$ & 0.695 \\
\hline
\end{tabular}

**Significant at $P<0.05$

South Africa and Rwanda, respectively [35, 36]. This is in line with findings in this study, as palpable mass accounts for $69.6 \%$ of all breast disorders. Similarly, the same was reported for breast diseases in pregnancy by a study conducted in eastern Nigeria [9]. Contrary to the above findings, inflammation of the breast was reported to be the most common among women in a Ghana study [28].

A slight left laterality of breast disorders was found in this study. Studies conducted in Ile-Ife, Ilesha, Port-Harcourt in Nigeria, reported a right sided preponderance of benign breast diseases. Their studies however did not indicate whether it was found in pregnancy or not but it was found among women in general $[8,27$, 37]. No statistically significant difference was observed between the left or the right laterality of breast cancer and clinical outcome [38]. However, reasons given for the conflicting reports of the laterality of breast cancer were detection bias, handiness of the patients and size differences of the patients breasts $[39,40]$.

Findings from breast ultrasound scan showed majority of women had reactive axillary lymph nodes and prominent ducts. The prominent ducts are due to physiological changes in the breast during pregnancy and lactation. It appears as hypoechoic tubular structures on b-mode ultrasound scan; it represents ducts filled with colostrum and echogenic milk in late pregnancy and during lactation [13].

Lumps in pregnancy might not necessary be different from non pregnant state [30]. In this study, aside the reactive lymph nodes and prominent duct detected, fibroadenoma was the most frequent breast mass found at recruitment till six weeks postpartum, others were fibrocystic changes, breast cyst and galactocoele. Breast cyst, galactocoele were detected more at six months postpartum. In non pregnant state, several studies have widely reported fibroadenoma to be the commonest in young women [2, 3, 5, 8, 25, 27, 34, 37, 41, 42]. While in some studies conducted in Lagos and Maiduguri, both in Nigeria, it was documented to be second $[1,26]$.

Ezeonu et al. [9] also revealed fibroadenoma as the commonest breast disease during pregnancy and lactation in a study conducted in Abakaliki teaching hospital.

According to Bell et al. [11], fibroadenoma was the most common benign solid lesion that grows during pregnancy and breastfeeding due to increase hormones, however, galactocoele was found to be the commonest during lactation after cessation of breastfeeding. Another study reports fibroadenoma to be a common BBD among lactating women which can also present in third trimester, after delivery and breast feeding cessation while lactating adenoma was reported to be the commonest in pregnancy [34]. Joshi et al. [34] described lactating adenoma as masses that can mimic fibroadenoma and phylloides tumour, among others. These masses can reduce in size in third trimester and regress spontaneously after delivery [34]. While some believe lactational adenoma is a unique entity [10], Adeniji-Sofoluwe et al. 
[13] described sonographic findings of fibroadenoma and lactational adenoma to be indistinguishable but lactational adenoma may show posterior acoustic enhancement increased compressibility.

Even though three participants were referred for biopsy, breast cancer diagnosis was not made in this study. Ezeonu et al. [9] attributed the reason they found no malignant case in their study to participants characteristics such as their young age, young age at first childbirth and high parity. These reasons might be unlikely, as majority of palpable masses in pregnancy are known to be benign with a percentage of $73-88 \%$ also breast cancer is found more among young women in Nigeria [12, 43, 44]. Nevertheless masses found during pregnancy should not be delayed for evaluation as there might be increase in PABC due to the trend of delay in child bearing age [34].

An association was found between number of pregnancies and breast disorders in this study. After adjusting for confounders, women with 3 or more pregnancies had lower odds for breast disorders compared to those who had one. This is interesting as increasing parity is an established factor for reduced breast cancer risk among women in general, this was also noted in a Nigerian study [45]. Fibroadenoma risk also reduces with increasing number of full term pregnancy in a study conducted in Ogun state, Nigeria [3].

Other patients' characteristic associated with lower odds of breast disorders in this study is having a bachelor's level of education compared to those with none or primary level of education. Variables associated with higher odds for breast disorders were a history of previous benign breast diseases and being a full time housewife or unemployed.

\section{Limitations of the study}

Approximately $40 \%$ of women referred for ultrasound scan did not show up, in addition, there were delay from CBE to BUS uptakes. These may affect some of the findings in this study as lower proportion of masses were found in the ultrasound reports compared to $\mathrm{CBE}$. Fear and activities of alternative or traditional medicine are reasons that could account for not appearing for BUS [3]. Misclassification bias arising from different nurses with different level of experience could have affected the definition of breast disorder during breast examination and this might have affected findings in this study. Misclassification bias was however reduced because the nurses were trained together prior to the commencement of this study and the inter-rater agreement was moderate. Also, some participants who were not seen at their 6 weeks postpartum and 6 months postpartum clinic visit were called and asked for any noticeable breast changes to reduce loss to follow up.

\section{Conclusion and recommendations}

This study found a substantial number of pregnant women with breast lumps detected by CBE. We found fibroadenoma to be the commonest breast disease in pregnancy and at six weeks postpartum, while breast cyst and galactocoele were found at six weeks and six months postpartum. The incidence of breast disorders detected by CBE was 9.2 per 100 person years in pregnancy and lactation. The risk of breast disorders detected through $\mathrm{CBE}$ reduced with time in pregnancy and lactation.

We recommend breast screening like CBE to be done twice during pregnancy, at ANC registration and once in third trimester. For lactating women, $\mathrm{CBE}$ should be done at 6 weeks postpartum. However, those found with breast disorders should be referred immediately for BUS and ultrasound guided biopsy.

Antenatal and postnatal clinics should be considered a place for intensified screening and teaching of breast education. This is a feasible and very useful option for early breast cancer diagnosis. As close to $60 \%$ of women in their reproductive ages who attend ANC at least once in pregnancy according to National Demographic Health Survey 2013 [46] would be captured. Due to the challenging nature of examining the breast during pregnancy and lactation, health care workers should be trained on how to conduct thorough $\mathrm{CBE}$ using standard and validated techniques. Further diagnostic investigations such as BUS and ultrasound guided biopsy should be conducted after breast disorders are found during CBE. Factors affecting low diagnostic uptake should be addressed by educating the women. Studies with longer follow up duration could have possibly found cases of PABC, in addition, it could as well determine the risk of breast cancer after breast disorder diagnosis.

\section{Abbreviations \\ ANC: Antenatal clinics; BBD: Benign breast diseases; BIRADS: Breast imaging reporting and data system; BSE: Breast self examination; BUS: Breast ultrasound scan; CBE: Clinical breast examination; GEE: Generalized estimating equation; GLMM: Generalized linear marginal model; PABC: Pregnancy associated breast cancer; UI/UCH: University of Ibadan/ University College Hospital}

\section{Acknowledgements}

The study would acknowledge all pregnant women who gave their informed consent and participated in the study.

\section{Funding}

This project was supported by NIH D43 re-entry grant by the University of Ibadan and the University of Chicago international partnership for interdisciplinary Research training team.

Availability of data and materials

The datasets used and/or analysed during the current study are available from the corresponding author on reasonable request.

\section{Authors' contributions}

SOO designed the study, collected, analysed the data and drafted the manuscript: IOA participated in the study design, supervised data collection and implementation of study, and participated in the revision of the 
manuscript; AAS performed and interpreted the breast ultrasound scan and performed the ultrasound guided biopsy: IOM participated in the study concept and design; DH supervised implementation of study, data analysis and interpretation, and participated in the manuscript revision; OAO supervised the study's implementation and was involved with manuscript revision; OIO supervised the study's implementation and was involved with manuscript revision. All authors read and approved the final manuscript.

\section{Ethics approval and consent to participate}

Ethical approval was granted by the University of Ibadan/University College Hospital (UI/UCH) Ethics Committee (NHREC/05/01/2008a) and the study was assigned number UI/EC/14/009. Ethical review at the UCH was renewed for the years 2016, and 2017, respectively. Ethical approval was also obtained from the Oyo State Ministry of Health Ethics Committee, Ibadan, Nigeria. There was written permission to conduct the study at the University College Hospital, Obstetrics and Gynaecology unit, Adeoyo State Hospital, Yemetu, and Ibadan South-East Local Government. All participants gave their written informed consent.

\section{Consent for publication}

Not applicable.

\section{Competing interests}

The authors declare that they have no competing interests.

\section{Publisher's Note}

Springer Nature remains neutral with regard to jurisdictional claims in published maps and institutional affiliations.

\section{Author details \\ ${ }^{1}$ Department of Epidemiology and Medical Statistics, Faculty of Public Health, University of Ibadan, Ibadan, Nigeria. ${ }^{2}$ Department of Radiology, Faculty of Clinical Sciences, University of Ibadan, Ibadan, Nigeria. ${ }^{3}$ Centre for Population and Reproductive Health, College of Medicine, Ibadan, Nigeria. ${ }^{4}$ Department of Obstetrics and Gynaecology, Faculty of Clinical Sciences, College of Medicine, University of Ibadan, Ibadan, Nigeria. ${ }^{5}$ Department of Public Health Sciences, University of Chicago, Chicago, IL, USA. ${ }^{6}$ Center for Global Health, University of Chicago, Chicago, IL, USA}

Received: 5 June 2018 Accepted: 12 September 2018 Published online: 19 September 2018

\section{References}

1. Nggada HA, Gali BM, Bakari AA, Yawe-Terna EH, Tahir MB, Apari E, Dahiru $A B$, Yawe K-DT. The spectrum of female breast diseases among Nigerian population in Sahel climatic zone. J Med Med Sci. 2011;2:1157-61.

2. Nuhu A, Musa AB, Aliyu S. Management of breast lumps in Maiduguri, Nigeria. Sahel Med J. 2014;17:50.

3. Ayoade BA, Tade AO, Salami BA. Clinical features and pattern of presentation of breast diseases in surgical outpatient clinic of a suburban tertiary hospital in south-West Nigeria. Niger J Surg. 2012;18:13-6.

4. Okoth C, Galukande M, Jombwe J, Wamala D. Benign proliferative breast diseases among female patients at a sub Saharan Africa tertiary hospital: a cross sectional study. BMC Surg. 2013;13:1-5.

5. Hartmann LC, Sellers TA, Frost MH, Lingle WL, Degnim AC, Karthik Ghosh K, Vierkant RA, Maloney SD, Pankratz VS, Hillman DW, et al. Benign breast disease and the risk of breast Cancer. N Engl J Med. 2005;353:229-37.

6. Goldacre MJ, Abisgold JD, Yeates DG, Vessey MP. Benign breast disease and subsequent breast cancer: English record linkage studies. J Public Health. 2010;32:565-71.

7. Ntekim A, Nufu FT, Campbell OB. Breast cancer in young women in Ibadan, Nigeria. Afr Health Sci. 2009;9:242-6.

8. Forae $\mathrm{G}$, Igbe A, ljomone E, Nwachokor F, Odokuma E. Benign breast diseases in Warri Southern Nigeria: a spectrum of histopathological analysis. Ann Niger Med. 2014;8:28.

9. Ezeonu PO, Ajah LO, Onoh RC, Lawani LO, Enemuo VC, Agwu UM. Evaluation of clinical breast examination and breast ultrasonography among pregnant women in Abakaliki, Nigeria. Onco Targets and Ther. 2015;2015:1025-9.

10. Saria MS, Mirza MR. Breast diseases presenting during pregnancy and lactation. J Surg Pakistan (International). 2010;15:147-50.
11. Bell H, Peters G, Lynch A, Harle R. Breast disorders during pregnancy and lactation: the differential diagnoses. J Clin Gynecol Obstet. 2013. https://doi. org/10.4021/jcgo140w.

12. Langer A, Mohallem M, Berment H, Ferreira F, Gog A, Khalifa D, Nekka I, Cherel P. Breast lumps in pregnant women. Diagn Interv Imaging. 2015;96: 1077-87.

13. Adeniji-Sofoluwe AT, Obajimi GO, Obajimi MO. Pregnancy related breast diseases in a developing African country: initial Sonographic evaluation. Pan African Med J. 2015;20:239.

14. Cote ML, Ruterbusch JJ, Alosh B, Bandyopadhyay S, Kim E, Albashiti B, Sharaf Aldeen B, Radisky DC, Frost MH, Visscher DW, et al. Benign breast disease and the risk of subsequent breast cancer in African American women. Cancer Prev Res (Phila). 2012:5:1375-80.

15. Keinan-Boker L, Lerner-Geva L, Kaufman B, Meirow D. Pregnancy-associated breast Cancer. Israel Med Assoc J. 2008;1:722-7.

16. Johansson ALV, Andersson T-L, Hsieh CC. Increased mortality in women with breast cancer detected during pregnancy and different periods postpartum. Cancer Epidemiol Biomarkers Prev. 2011;20:1865-72.

17. Abuidris DO, Elsheikh A, Ali M, Musa H, Elgali E, Ahmed AO, Sulieman I, Mohammed SI. Breast-cancer screening with trained volunteers in a rural area of Sudan: a pilot study. Lancet Oncol. 2013;14:363-70.

18. Oluwatosin OA, Oladepo O. Knowledge of breast cancer and its early detection measures among rural women in Akinyele local government area, Ibadan Nigeria. BMC Cancer. 2006;6:271

19. Lyons TR, Schedin PJ, Borges VF. Pregnancy and breast cancer: when they collide. J Mammary Gland Biol Neoplasia. 2009;14:87-98.

20. Bevers TB, Anderson BO, Bonaccio E, Buys S, Daly MB, Dempsey PJ, Farrar WB, Fleming I, Garber JE, Harris RE, et al. Breast Cancer screening and diagnosis. Natl Compr Canc Netw. 2009;7:1060-96.

21. NPC: The Population Commision of Nigeria. Report of the Final 2006 Census Result. 2007. https://www.population.gov.ng. Accessed 19 Jul 2018.

22. Lwanga SK, lemeshow S. Sample size determination in health studies: a practical manual. Germany: WHO; 1991. p. 17-8.

23. Galvan-Portillo M, Torres-Sanchez L, Lopez-Carrillo L. Dietary and reproductive factor associated with benign breast disease in Mexican women. Nutr Cancer. 2002:43:133-40.

24. Barton MB, Russell H, Fletcher SW. Does this patient have breast cancer? The screening clinical breast examination: should it be done? How? J Am Med Assoc. 1999;283:1270-80.

25. Olu-Eddo AN, Ugiagbe EE. Benign breast lesions in an African population: a 25-year histopathological review of 1864 cases. Nig Med J. 2011:52:211-6.

26. Jeje EA, Mofikoya BO, Oku YE. Pattern of breast masses in Lagos: a private health facility review of 189 consecutive patients. Nig Q J Hosp Med. 2010; 20:38-41.

27. Adeniji KA, Adelusola KA, Odesanmi WO. Benign disease of the breast in lle-Ife: a 10 year experience and literature review. Cent Afr J Med. 1997;43:140-3.

28. Ghartey FN, Anyanful A, Eliason S, Adamu SM, Debrah S. Pattern of breast Cancer distribution in Ghana: a survey to enhance early detection, diagnosis, and treatment. Int J Breast Cancer. 2016. https://doi.org/10.1155/ 2016/3645308.

29. Lukanova A, Surcel HM, Lundin E, Kaasila M, Lakso HA, Schock H, Husing A, Kaaks R, Koskela P, Grankvist K, et al. Circulating estrogens and progesterone during primiparous pregnancies and risk of maternal breast cancer. Int J Cancer. 2012;130:910-20.

30. Yu JH, Kim MJ, Cho H, Liu HJ, Han SJ, Ahn TG. Breast diseases during pregnancy and lactation. Obstet Gynecol Sci. 2013;56:143-59.

31. Agbo PS, Khalid A, Oboirien M. Clinical presentation, prevalence and Management of Breast Cancer in Sokoto, Nigeria. J Women's Health Care. 2014;03:1-5.

32. Hou N, Ogundiran T, Ojengbede O, Morhason-Bello I, Zheng Y, Fackenthal J, Adebamowo C, Anetor I, Akinleye S, Olopade Ol, et al. Risk factors for pregnancy-associated breast cancer: a report from the Nigerian breast Cancer study. Ann Epidemiol. 2013;23:551-7.

33. Freire de Oliveira C. Oral contraceptives and benign diseases. Fertil Control Rev. 1995:4:19-22.

34. Joshi S, Dialani V, Marotti J, Mehta TS, Slanetz PJ. Breast disease in the pregnant and lactating patient: radiological-pathological correlation. Insights Imaging. 2013:4:527-38.

35. Rayne S, Lince-Deroche N, Hendrickson C, Shearer K, Moyo F, Michelow P, Rubin G, Benn C, Firnhaber C. Characterizing breast conditions at an openaccess breast clinic in South Africa: a model that is more than cancer care for a resource-limited setting. BMC Health Serv Res. 2017;17:63. 
36. Pace LE, Dusengimana JV, Hategekimana V, Habineza H, Bigirimana JB, Tapela N, Mutumbira C, Mpanumusingo E, Brock JE, Meserve E, et al. Benign and malignant breast disease at Rwanda's first public Cancer referral center. Oncologist. 2016;21:571-5.

37. Adesunkanmi AR, Agbakwuru EA. Benign breast disease at Wesley Guild hospital, llesha, Nigeria. West Afr J Med. 2001;20:146-51.

38. Zeeneldin AA, Ramadan M, Elmashad N, Fakhr I, Diaa A, Mosaad E. Breast cancer laterality among Egyptian patients and its association with treatments and survival. J Egypt Natl Canc Inst. 2013;25:199-207.

39. Senie RT, Rosen PP, Lesser ML, Snyder RE, Schottenfeld D, Duthie K. Epidemiology of breast carcinoma II: factors related to the predominance of left-sided disease. Cancer. 1980;46:1705-13.

40. Badru F, Chianakwalam C, Stevenson V. Laterality of breast Cancer - is it true? Eur J Surg Oncol. 2011;37:987.

41. Pearlman MD, Griffin JL. Benign breast disease. Obstet Gynecol. 2010;116: $747-58$.

42. Berkey CS, Willett WC, Frazier AL, Rosner B, Tamimi RM, Colditz GA. Prospective study of growth and development in older girls and risk of benign breast disease in young women. Cancer. 2011;117:1612-20.

43. Buré LA, Azoulay L, Benjamin A, Abenhaim HA. Pregnancy-associated breast Cancer: a review for the obstetrical care provider. J Obstet Gynaecol Can. 2011:33:330-7.

44. Khurshid A, Faridi N, Arif AM, Naqvi H, Tahir M. Breast lesions in adolescents and young women in Pakistan - a 5 year study of significance of early recognition. Asian Pac J Cancer Prev. 2013;14:3465-7.

45. Huo D, Adebamowo CA, Ogundiran TO, Akang EE, Campbell O, Adenipekun A, Cummings S, Fackenthal J, Ademuyiwa F, Ahsan $\mathrm{H}$, et al. Parity and breastfeeding are protective against breast cancer in Nigerian women. $\mathrm{Br}$ J Cancer. 2008;98:992-6.

46. NDHS: Nigeria demographic and health Survey. 2013. https://dhsprogram. com/pubs/pdf/GF34/GF34.pdf. Accessed 20 Nov 2017.

Ready to submit your research? Choose BMC and benefit from:

- fast, convenient online submission

- thorough peer review by experienced researchers in your field

- rapid publication on acceptance

- support for research data, including large and complex data types

- gold Open Access which fosters wider collaboration and increased citations

- maximum visibility for your research: over $100 \mathrm{M}$ website views per year

At $\mathrm{BMC}$, research is always in progress.

Learn more biomedcentral.com/submissions 